\title{
Intoxication of Cypermethrin on Binding Site of Human Oxyhaemoglobin
}

\author{
Dr. Padma Saxena ${ }^{1 *}$
}

\author{
${ }^{1}$ Assistant Professor-Department of Zoology Sri Tikaram Kanya Mahavidyalaya, Aligarh (U.P.) India

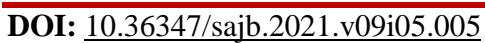 \\ | Received: 03.05.2021 | Accepted: 21.05.2021 | Published: 30.05.2021 \\ *Corresponding author: Dr. Padma Saxena \\ Abstract \\ Original Research Article
}

Pesticide exposure can occur by several routes in the same individual due to multiple uses, and there is likely to be additive toxicity in human. Cypermethrin a synthetic pyrethroid can produce a variety of acute health conditions and also carries several ecological risks. Hemoglobin is the protein that transports oxygen in the blood. Any change in heamoglobin may direct or indirect effect the human body. In this work, we report computational prediction of binding of cypermethrin pesticides on human oxyhaemoglobin [using Molegro Virtual Docker (MVD)] and evaluating the computational prediction on binding of human oxyhaemoglobin with cypermethrin pesticide and evaluate the Mole Dock Score, RMSD, affinity, interacting residues of receptor human oxyhaemoglobin, number of H-bond interaction, docking score and intracting interaction of residues. The energy bound conformation with lower value of selected ligand shows hydrogen bonding and electrostatic interactions. The binding affinity of cypermethrin pesticides is found to be $-35.7414 \mathrm{KJ} / \mathrm{mol}$, and bind with two hydrogen bonds with tyrosine 35 and serine 133 . Frequent alterations in the expression of amino acid due to pesticide interaction with oxyhemoglobin may lead to produce carcinogenic cells in human beings.

Keywords: Synthetic Pyrethroid, Cypermethrin, Human oxyhaemoglobin, MVD, Tyrosine, Serine.

Copyright $(\mathcal{C} 2021$ The Author(s): This is an open-access article distributed under the terms of the Creative Commons Attribution 4.0 International License (CC BY-NC 4.0) which permits unrestricted use, distribution, and reproduction in any medium for non-commercial use provided the original author and source are credited.

\section{INTRODUCTION}

Pesticides are designed to kill but their mode of action is not specific to one species, they often kill or harm organisms other than pests, including humans (Yousef et al., 2003). The application of pesticides is often not very precise, and unintended exposures occur to other organisms in the general area where pesticides are applied. They can cause acute as well as chronic adverse health problems and environmental contamination worldwide (Dich et al. 1997, Soares et al., 2003; Remor et al., 2009). Pyrethroids were developed as a synthetic version of the naturally occurring pesticide pyrethrin, which is found in chrysanthemums. Cypermethrin is a synthetic pyrethroid; a broad spectrum, non-cumulative insecticide and a fast-acting neurotoxin with good contact and stomach action. It has of moderately high toxicity to non-target animals (Bradberry et al. 2005). Cypermethrin is primarily absorbed from the gastrointestinal tract than after move into circulatory system. All living systems depend on iron to transport (haemoglobin), store (myoglobin) and utilize (cytochromes, cytochrome oxide) oxygen for respiration. Iron is an essential component in the active sites of the enzyme that protects against oxidation (Anastassopoulou et al. 2000). The blood composition of living animal reflects tissue metabolism, it become necessary to carry out hematological examination to evaluate the normal and abnormal physiological states of the body. Computational methods provide aids for not only designing and interpretation of hypothesis driven experiments in the field of drug discovery research but may also be used to compare in vitro results for rapid generation of new hypotheses. Even today our understanding of the relationship between pesticides and human health is limited due to numerous methodological problems faced in laboratory studies. Computational methods can turn out very useful for comparing vitro results for new hypotheses (Saxena 2013).

\section{MATERIALS AND METHODS}

Three dimensional X ray crystallized structure of human oxyhaemoglobin (PDB:1HHO, 2.1 A resolution ) was downloaded from the Protein Data Bank (Shaanan, 1983). The downloaded protein have two chain HEMOGLOBIN A (OXY) (ALPHA CHAIN) with 141 residues and HEMOGLOBIN A (OXY) (BETA CHAIN) with 146 residues (Fig-1). The protein was taken as receptor protein and most suitable site was predicted by using $\mathrm{q}$ site finder ligand binding site prediction (http://www.modelling.leeds.ac.uk). On the 
basis of priority of site, oxyhaemoglobin has been selected for docking with ligand cypermethrin a synthetic pyrthroid. The selected ligand was downloaded from Pub Chem Compound Fig-2 (http://www.ncbi.nlm.nih.gov).

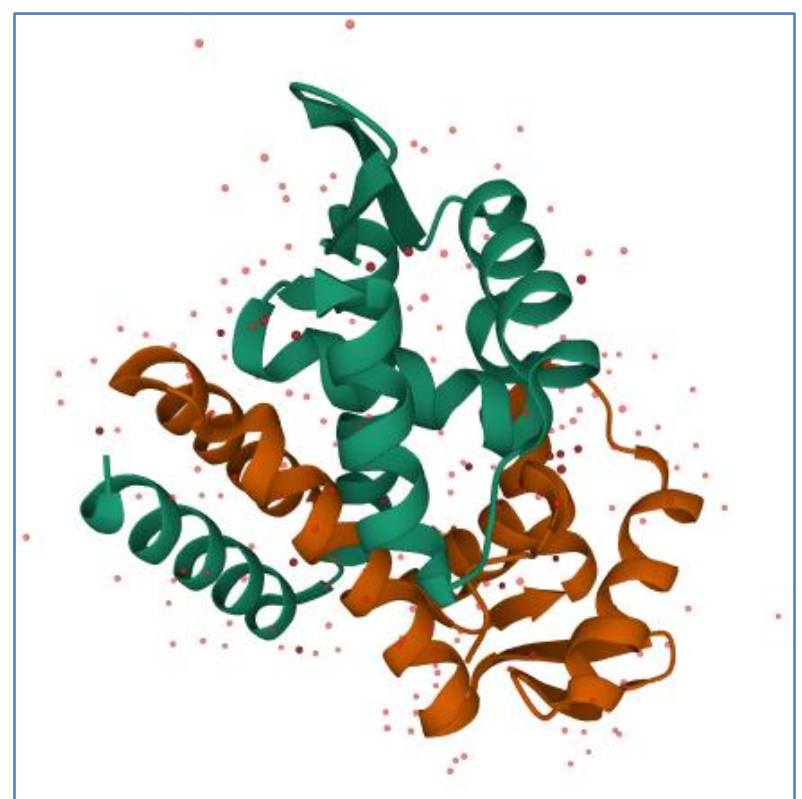

Fig- 1 Structure of Haemoglobin (PDB: 1HHO, $2.1 \AA$ resolutions)

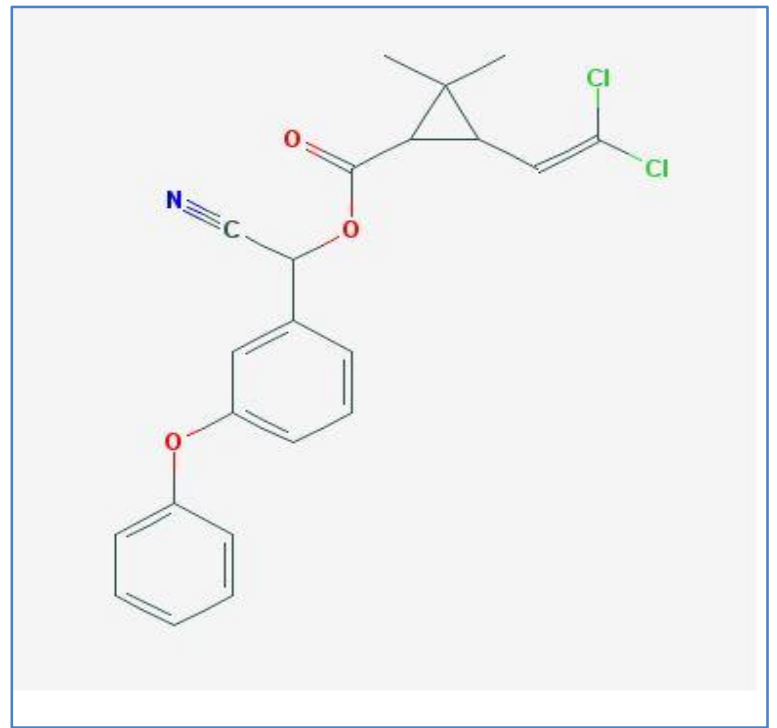

Fig-2: Structure of Cypermethrin (http://www.ncbi.nlm.nih.gov)

Docking study was done with MVD it is automated docking software with fast processing. It shows MoleDockScore, hydrogen bond information together with other thermodynamic values, which suggest the formation of stable complex between ligand and receptor molecule (Thomsen and Christensen 2006).

\section{RESULT AND DISCUSSION}

The results obtained using MVD shown in terms of Mole Dock Score, RMSD, Affinity (the estimated binding affinity in $(\mathrm{kj} / \mathrm{mol}))$, interacting residues of receptor human oxyhaemoglobin, number of $\mathrm{H}$-bond interaction, docking score and interacting interaction (the interaction energy between the pose and the cofactor) Table 1 .

Table -1 Comparative Docking Simulation Result of Cypermethrin Pesticide with Human Oxyhaemoglobin (PDB: 1HHO) using MVD

\begin{tabular}{|l|l|l|l|l|l|}
\hline S.No & Mole Dock Scor & RMSD & Affinity & Intracting & Docking Score \\
\hline 1. & -146.857 & 2.2572 & -38.8334 & -162.946 & -106.308 \\
\hline 2. & -142.632 & 0.414659 & -36.3776 & -151.259 & -111.019 \\
\hline 3. & -128.734 & 1.20664 & -37.3876 & -139.452 & -102.921 \\
\hline 4. & -123.793 & 7.18647 & -35.5267 & -131.386 & -92.1953 \\
\hline 5. & -125.637 & 8.15067 & -36.9612 & -145.691 & -96.1466 \\
\hline
\end{tabular}

MVD and its visualizer were used for interaction site analysis (Singh et al., 2012). The interaction analysis for binding of cypermethrin with human oxyhaemoglobin has been done to find out the residues that are involved in binding. The cypermethrin shows very high affinity to bind with B chain of human oxyhaemoglobin and it interacts with Leu 105, Tyr 35, Asn 108 similarly with A chain of human oxyhaemoglobin and it interacts with Pro 95, Thr 134, Phe98, Ser 133, Ala 130, Lys 99, Leu100, Ser102, Asp126 and His 103 residues of human oxyhaemoglobin (Table -2, Fig.- 3) .
All these residues involved in binding belong to the cavity-1. The cypermethrin forms 2 hydrogen bonds with Tyr 35and Ser 133.The binding of pesticide with oxyhaemoglobin also supported by in vitro studies. Saxena \&Saxena 1997 reported a fall in hemoglobin contents after cybil (synthetic pyrethroid) intoxication in albino rats. Further, Shakoori et al. (1988), Saxena et al. (2009), Shah et al. (2007) and Jayakumar et al. (2008) also observed a significant reduction in heamoglobin concentration after cypermethrin toxicity. 
Padma Saxena., Sch Acad J Biosci, May, 2021; 9(5): 145-148

Table -2: Human Oxyhaemoglobin (PDB: 1HHO) protein residues interact with Cypermethrin pesticide using MVD (Highlighted residues are involved in $\mathrm{H}$-bonding interaction with ligands)

\begin{tabular}{|l|l|l|l|}
\hline S. No. & ligand & Interacting residues of receptor Human oxyhaemoglobin & $\begin{array}{l}\text { No. of H-bond } \\
\text { interaction }\end{array}$ \\
\hline 1. & Cypermethrin & $\begin{array}{l}\text { Leu 105, Tyr 35, Asn 108, Pro 95, Thr 134, Phe98, Ser 133, } \\
\text { Ala 130, Lys 99, Leu100, Ser102, Asp126 and His 103 }\end{array}$ & 02 \\
\hline
\end{tabular}

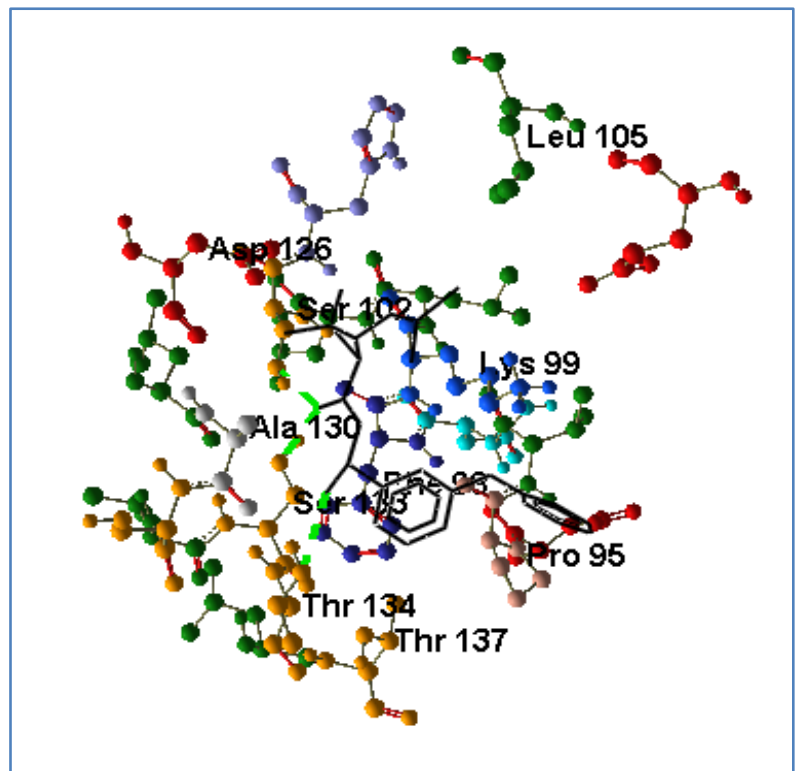

Fig-3: Docked conformation of hydrogen bonding view of cypermethrin with interacting Human Oxyhaemoglobin protein at the active site cavity

Docking study shows that amino acid residues i.e Tyr 35 and Ser 133bind with cypermethrin. Tyrosine is a non-essential amino acid with a polar side group. Miki et al. (1989) and Svistunenko et al. 2002 reported that a tyrosine residue was involved in free radical formation after the reaction of heme proteins with peroxides.Serine is also polar amino acid and important for catalytic function of many enzymes (Serine, 2013).The most of the degenerative diseases that afflict humanity have their origin in deleterious free radical reactions. Frequent alterations in the expression of amino acid due to pesticide interaction with oxyhemoglobin may lead to produce atherosclerosis, cancer, inflammatory joint disease, asthma, diabetes, senile dementia and degenerative eye disease (Florence, 1995) in human beings.

\section{REFERENCE}

1. Anastassopoulou, J., Anifantakis, B., Anifantakis, Z.A., Dovas, A., Theophanides, T. (2000). The role of free radical reactions with haemoglobin and thalassaemia. J Inorg Biochem.79 (1-4):327-9.

2. Bradberry, S. M., Cage, S. A., Proudfoot, A. T., Vale, J. A. (2005). Poisoning due to Pyrethroids. Toxicol. Rev., 24 (2); 93-106.

3. Dich, J., Zahm, S.H., Hanberg, A., Adami, H.O. (1997). Pesticides and cancer. Cancer Causes Control. 8:420-43

4. Florence, T.M. (1995). The role of free radicals in disease. Aust N Z J Ophthalmol, 23 (1):3-7
5. Jayakumar, R., Nagarjuna, A., Deuraju, T., Jayantha. R. (2008). Alteration of Haematological Profiles due to cypermethrin Toxicosis in Rana hexadactyla. J Indian Society of Toxicology, 4(2); 973-3558

6. Miki, H., Harada, K., Yamazaki, I., Tamura, M., Watanabe, H. (1989). Electron-spin resonance-spectrum of Tyr-151 free-radical formed inreactions of sperm whale metmyoglobin with ethyl hydroperoxide and potassium irridate. Arch. Biochem. Biophys, 275; 354-362.

7. Remor A.P. Totti C.C., Moreira D.A., Dutra G.P., Heuser, V.D., Boeira, J.M. (2009). Occupational exposure of farm workers to pesticides: Biochemical parameters and evaluation of genotoxicity. Environ. Int. 35, 273-278.

8. Saxena, P. (2013). Computational Prediction of Binding of Methyl carbamate, Sarin, Deltamethrin and Endosulfan Pesticides on Human Oxyhaemoglobin. Jordan Journal of biological Sciences, 6(4): 320-323

9. Saxena, P., Saxena, V.L., \& Saxena, A.K. (2009). Cypermethrin induced toxicity in the blood of Rattus norvegicus. Trends in Life Sci, 24(1 ): 59-63

10. Saxena, P.N., \& Saxena, P. (1997). Haemogrammic studies in albino rat after Cybil intoxication. J Environ Biol, 18 (4); 425-428

11. Serine. (2013). The Columbia Encyclopedia, $6^{\text {th }}$ ed. Encyclopedia.com. 25Jun. 2013<http:// www. encyclopedi.com>.

12. Shaanan, B.

Structure of human oxyhaemoglobin at 2.1 A resol ution. J. Mol. Biol. 171; 31-59

13. Shah, M.K., Khan, A., Rizvi, F., Siddique, M., \& Rehman, S.U. (2007). Effect of cypermethrin on clinico-haematological parameters in rabbits. Pak Vet J. 27(4); 171-175.

14. Shakoori, A.R., Ali, S.S., \& Saleem, M.A. (1988) Effect of six months feeding of cypermethrin on the blood and liver of albino rat. J Biochem Toxicol. 3; 59-71.

15. Singh, D.V., Agarwal, S., Kesharwani, R.K., Misra, K. (2012). Molecular modeling and computational simulation of the photosystem-II reaction center to addressisoproturon resistance in Phalaris minor. J Mol Model, 18; 3903-3913.

16. Soares, W., Almeida, R.M.V.R., Moro, S. (2003). Rural work and risk factors associated with pesticide use in Minas Gerais, Brazil. Cad. Saúde Pública. 19; 1117-1127.

17. Svistunenko, D., Dunne, A.J., Fryer, M., Nicholls, P., Reeder, B. J., Wilson, M. T., Bigotti, M. G., Cutruzzola, F., Cooper C. E. (2002). Comparative 
Padma Saxena., Sch Acad J Biosci, May, 2021; 9(5): 145-148

Study of Tyrosine Radicals in Hemoglobin and Myoglobins Treated with Hydrogen Peroxide. Biophysical Journal, 83; 2845-2855

18. Thomsen, R., Christensen, M.H. (2006). MolDock: a new technique for high-accuracy molecular docking. J Med Chem, 49(11); 3315-3321.
19. Yousef, M.I., El-Demerdash, F.M., Kamel, K.I., Al, Salhen, K.S. (2003). Chages in Some hematological and biochemical indices of rabbits induced by isoflavones and cypermethrin. Toxicol. 189; 223-234 